\title{
A survey on critical health competences among diabetes educators using the Critical Health Competence Test (CHC Test)
}

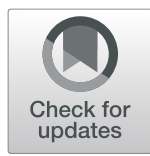

Lars Hecht $^{1 *}$, Gabriele Meyer ${ }^{2}$ and Anke Steckelberg ${ }^{2}$

\begin{abstract}
Background: Diabetes associations claim to have a patient-centered approach in diabetes care including shared decision-making (SDM). Diabetes educators are important healthcare professionals for implementing the concept of informed SDM in diabetes care. They need critical health competences (CHC) in order to provide evidence-based information and to support patients in understanding the risks of the disease and also the possible benefits or harm of the healthcare options. Therefore, we surveyed the $\mathrm{CHC}$ of diabetes educators.

Methods: We performed a cross-sectional survey using the validated Critical Health Competences (CHC) Test to measure CHC of certified diabetes educators and trainees in Germany. Diabetes educators were approached via newsletter, mailing lists or in person during the conference of the German Diabetes Association. Trainees were approached during their training sessions. We applied scenario 1 of the $\mathrm{CHC}$ test, which comprises 17 items with open-ended and multiple-choice questions. Mean person parameters with a range from 0 to 1000 were calculated to assess the levels of critical health competences and a multiple linear regression analysis was conducted to determine correlations between sociodemographic variables and levels of $\mathrm{CHC}$.
\end{abstract}

Results: A total of 325 participants, mean age 38.6 ( \pm 11.1$)$ years, completed the CHC test; $n=174(55.5 \%)$ were certified diabetes educators and $n=151$ (46.5\%) were trainees. The participants achieved a mean score of 409.84 person parameters $( \pm 88.10)$ (scale from 0 to 1000). A statistically significant association was found only between the level of education and the level of CHC ( $b=0.221$; $p$-value 0.002). Participants with grammar school education achieved higher mean scores compared to participants with secondary school education (432.88 \pm 77.72 vs. $396.45 \pm 85.95$; mean difference $36.42 \pm 9.29 ; 95 \%$ Cl 18.15 to $54.71 ; p<0.0001$ ).

Conclusion: Diabetes educators achieved low competence scores and it can be assumed that they do not have sufficient $\mathrm{CHC}$ to conduct consultations based on the SDM principles. Poor $\mathrm{CHC}$ among healthcare providers are a major barrier for the implementation of SDM. Core concepts of evidence-based medicine should be implemented into the curricula for diabetes educators in order to increase their levels of $\mathrm{CHC}$.

Keywords: Critical health competence, Critical health literacy, Evidence-based medicine, Evidence-based practice, Diabetes, Diabetes educator, Shared decision-making

\footnotetext{
* Correspondence: hecht@red-institut.de

'School of Nursing Science, Faculty of Health, University of Witten/Herdecke, Witten, Herdecke, Germany

Full list of author information is available at the end of the article
}

(c) The Author(s). 2021 Open Access This article is licensed under a Creative Commons Attribution 4.0 International License, which permits use, sharing, adaptation, distribution and reproduction in any medium or format, as long as you give appropriate credit to the original author(s) and the source, provide a link to the Creative Commons licence, and indicate if changes were made. The images or other third party material in this article are included in the article's Creative Commons licence, unless indicated otherwise in a credit line to the material. If material is not included in the article's Creative Commons licence and your intended use is not permitted by statutory regulation or exceeds the permitted use, you will need to obtain permission directly from the copyright holder. To view a copy of this licence, visit http://creativecommons.org/licenses/by/4.0/ The Creative Commons Public Domain Dedication waiver (http://creativecommons.org/publicdomain/zero/1.0/) applies to the data made available in this article, unless otherwise stated in a credit line to the data. 


\section{Background}

Patients increasingly prefer active roles in healthcare decision-making. They want to be involved in healthrelated decisions, regardless of their current medical condition, age or sex [1-5]. Health authorities have highlighted the need to involve patients in the development and supply of healthcare, and request informed shared decision-making (SDM), where patients and healthcare providers simultaneously participate by sharing information and jointly negotiating the treatment options $[6,7]$. In the informed SDM process, evidencebased information, including benefits and harm of all treatment options, has to be provided and patients' values and preferences have to be clarified. The healthcare professional needs at least to explain the treatment options and their possible consequences for the patient $[8,9]$. As a result, an informed choice can be made which is based on relevant knowledge, and the decisionmaker's attitude is consistent with the chosen option [8]. However, several barriers in the implementation of informed shared decision-making in clinical practice have been identified. Structural factors such as lack of time as well as a power imbalance in the relationship between the patient and the healthcare professional have been stated [10, 11]. Another major barrier is found in the poor CHC among healthcare providers [12]. The World Health Organizations' healthy schools initiative defines health literacy as "... the cognitive and social skills, which determine the motivation and ability of individuals to gain access to understand and use information in ways which promote and maintain good health" [13]. Health literacy is a complex construct with different dimensions and it has been defined in multiple ways. It concerns the motivation, knowledge and competences a person needs to understand, appraise and apply healthrelated information to improve their own health [14]. The well-established model of health literacy by Nutbeam distinguishes between three levels of health literacy:functional -, interactive -, and critical health literacy. Critical health literacy includes higher level of cognitive and social skills required to critically appraise different information and to engage in informed SDM [15]. So, a high level of $\mathrm{CHC}$ can enhance patient autonomy with regard to therapeutic decisions.

In the field of diabetes mellitus, informed SDM plays an important role. People with diabetes mellitus are subjected to many behavioral recommendations, such as adhering to dietary and medication prescriptions or concrete advice for reducing their bodyweight. The American Diabetes Association (ADA) and the European Association for the Study of Diabetes (EASD) claim a "patient-centered approach" in the care of people with diabetes. These approaches explicitly include informed SDM in diabetes therapy [16].
In Germany, diabetes educators could play a pivotal role in implementing the concept of informed SDM. Diabetes educators are healthcare professionals with a nursing or nutritional background who teach patients with diabetes mellitus to manage their condition and support them in doing so. As a prerequisite for providing informed SDM, diabetes educators need competences to critically appraise and appropriately communicate scientific information. Training to become a diabetes educator comprises $1800 \mathrm{~h}$ of partly theoretical and partly practical education [17]. However, the concept of evidence-based medicine is not consistently part of the training. Former studies suggested that diabetes educators overestimate the effects of therapeutic interventions when results of clinical trials are promoted in a biased way, and risk literacy is still low among this group of healthcare professionals [18]. Hence, we aimed to survey $\mathrm{CHC}$ in diabetes educators. To measure $\mathrm{CHC}$ of diabetes educators we used the validated $\mathrm{CHC}$ test developed by Steckelberg et al. [19].

\section{Methods \\ Study design}

The cross sectional survey aimed to measure $\mathrm{CHC}$ of specialized healthcare professionals.

\section{Participants}

Eligible participants for the survey were certified diabetes educators working in outpatient or inpatient settings and trainees. Healthcare professionals, who belonged to one of these groups and who expressed willingness, were invited to participate in the study.

\section{Recruitment}

The recruitment comprised three different strategies. First, announcements were published via newsletters and mailing lists. If one of the addressed healthcare professionals responded and expressed interest, the questionnaire was sent to the potential participant via email. Second, diabetes educators attending the conference of the German Diabetes Association in May 2018 were invited to participate. Third, trainees were contacted during their training sessions held in a training facility of the German Diabetes Association and invited to participate. These trainees had just started their $1800 \mathrm{~h}$ of theoretical and practical training. They were invited to complete the questionnaire during one of their training sessions Recruitment was carried out between October 2017 and February 2019.

\section{Outcomes}

The primary outcome was $\mathrm{CHC}$, as assessed by the CHC-test [19]. The secondary outcomes were correlations between sociodemographic variables and levels of 
critical health competences and corresponding differences in levels of competence.

The $\mathrm{CHC}$-test is a feasible and valid instrument for measuring critical health competences and comprises different content areas of health care. These topics are transformed into scenarios resulting in items. The items cover major competences and skills that belong to the critical health literacy construct: understanding of medical concepts, literature search skills as well as comprehension of basic statistics and study designs.

The complete $\mathrm{CHC}$-test includes four medical scenarios resulting in four test sheets with a total of 72 items. Reliability (WINMIRA ANOVA) across all items is 0.88 and for the single scenarios 0.74 (scenario 1); 0.68 (scenario 2); 0.69 (scenario 3) and 0.74 (scenario 4) [19].

Open-ended and multiple-choice questions were evenly distributed within the test. Completion of the all four test sheets did not exceed $90 \mathrm{~min}$.

However, single scenarios can be applied to measure $\mathrm{CHC}$ avoiding overload of the tested persons and increasing study participation.

To evaluate the level of $\mathrm{CHC}$, person parameters are calculated with a range from 0 to 1000 . Higher person parameters reflect a higher level of $\mathrm{CHC}$.

\section{Data collection}

In the present study, we applied scenario 1 with 17 items [19]. We chose scenario 1 , since the items of the first scenario were the simplest. Therefore, less competence (lower person parameters) is needed to solve the items of scenario 1. In order to achieve comparability of person parameters, we adjusted for different scenario difficulties.

Sociodemographic characteristics including sex, age, country of birth, level of education, profession and completed professional training in the field of health science were collected.

Diabetes educators who had been recruited via announcement returned the completed questionnaire via mail or email. Diabetes educators attending the conference of the German Diabetes Association in May 2018 were asked to fill in the questionnaire at the exhibition stand of the German Association of Diabetes Educators. Data collection for the trainees took place in three certified training centers run by the German Diabetes Association at the University of Applied Science of Rheine, the University of Jena and the Health Academy of Regensburg. Trainees were invited to complete the questionnaire during one of their training sessions.

\section{Data analysis}

DB and DA entered all the data in SPSS Version 21 according to the coding instruction. To ensure objective analyses, the coding rules for open-ended questions and the scoring rules for multiple choice items were applied. AS trained the coders to stick to the coding instructions and LH checked the data for accuracy. The baseline characteristics were analyzed descriptively. When applicable, means and SDs were calculated. Levels of $\mathrm{CHC}$ were assessed by calculating mean person parameters with a range from 0 to 1000 . A multiple linear regression analysis was performed to determine the correlations between sociodemographic variables and levels of $\mathrm{CHC}$. Through the multiple linear regression analysis, it was checked whether sex, age, country of birth, level of education, profession and completed professional trainings in the field of health science are significantly associated with the levels of $\mathrm{CHC}$. Mean person parameters were included as the dependent continuous variable. A $p$ value of $<0.05$ was considered statistically significant. The Student's t-test was applied to examine the differences in the levels of $\mathrm{CHC}$ among the relevant sociodemographic variables. Corresponding 95\% CIs were calculated to assess the range of differences in levels of competence.

\section{Ethical considerations}

The participants were informed about anonymized data collection and analysis. All the participants were free to answer the questions and all the diabetes educators in training were told that the survey was anonymous and had no impact on their grading.

The study was approved by the ethical committee of the Medical Faculty of the Martin Luther University Halle-Wittenberg (reference number 2017-75).

\section{Results}

Participants

A total of 325 participants, mean age $38.6( \pm 11.1)$ years, took part in the study and completed the questionnaires. The majority of participants was born in Germany. Only 21 participants originated from other countries and had lived in Germany for $21.6( \pm 11.8)$ years. The majority $(n=197)$ stated German as their native language, 17 participants had another native language and 111 did not respond to this question. The participants' average professional experience was $12.9( \pm 11.1)$ years. Approximately half of the participants $(46.2 \%)$ had completed advanced training in various fields of medicine; for example, study nurse or stroke nurse.

Table 1 displays the descriptive characteristics of the participants.

\section{Critical health competences}

The achieved mean score across all participants was 409.84 ( \pm 88.10$)$. A statistically significant association was found only between the level of education and the level of $\mathrm{CHC}$. The regression coefficient for the level of 
Table 1 Participants characteristics

\begin{tabular}{|c|c|c|}
\hline \multirow[t]{2}{*}{$\operatorname{Sex}(n=320)$} & \multirow{2}{*}{$\begin{array}{l}\text { Female } \\
\text { Male }\end{array}$} & \multirow{2}{*}{$\begin{array}{l}303 \\
(94.7 \%)^{a} \\
17(5.3 \%)\end{array}$} \\
\hline & & \\
\hline Age & $38.6( \pm 11.1)$ years & \\
\hline \multirow[t]{2}{*}{ Training status $(n=325)$} & Certified diabetes educator & $174(53.5 \%)$ \\
\hline & Trainee & $151(46.5 \%)$ \\
\hline \multirow[t]{2}{*}{ Level of education $^{\mathrm{b}}(n=316)$} & Secondary school & $176(55.5 \%)$ \\
\hline & Grammar school & $140(44.3 \%)$ \\
\hline \multirow[t]{10}{*}{ Basic profession $(n=322)$} & $\begin{array}{l}\text { State-examined nurse, } 3 \text { yrs. vocational } \\
\text { training }\end{array}$ & $106(32.9 \%)$ \\
\hline & Medical assistant & $84(26.1 \%)$ \\
\hline & Dietician & $83(25.8 \%)$ \\
\hline & Nutritional scientist & $30(9.3 \%)$ \\
\hline & More than one basic profession & $10(3.1 \%)$ \\
\hline & Physical therapist & $4(1.2 \%)$ \\
\hline & Medical technical assistant & $2(0.6 \%)$ \\
\hline & Pharmaceutical technical assistant & $1(0.3 \%)$ \\
\hline & Midwife & $1(0.3 \%)$ \\
\hline & Sports scientist & $1(0.3 \%)$ \\
\hline \multirow[t]{10}{*}{ Country of origin $(n=317$ ) } & Germany & $296(93.4 \%)$ \\
\hline & Russia & $5(1.6 \%)$ \\
\hline & Poland & $4(1.3 \%)$ \\
\hline & Turkey & $4(1.3 \%)$ \\
\hline & Kazakhstan & $2(0.6 \%)$ \\
\hline & Austria & $2(0.6 \%)$ \\
\hline & Switzerland & $1(0.3 \%)$ \\
\hline & Serbia & $1(0.3 \%)$ \\
\hline & Greece & $1(0.3 \%)$ \\
\hline & Portugal & $1(0.3 \%)$ \\
\hline \multirow[t]{8}{*}{ Native language $(n=214)$} & German & $197(91.6 \%)$ \\
\hline & Turkish & $5(2.3 \%)$ \\
\hline & Polish & $5(2.3 \%)$ \\
\hline & Russian & $3(1.4 \%)$ \\
\hline & Serbian & $1(0.5 \%)$ \\
\hline & Spanish & $1(0.5 \%)$ \\
\hline & Tamil & $1(0.5 \%)$ \\
\hline & Portuguese & $1(0.5 \%)$ \\
\hline Professional experience $(n=302)$ & $12.6( \pm 11.1)$ years & \\
\hline $\begin{array}{l}\text { Participants with completed advanced training in various fields of medicine ( } n= \\
\text { 316) }\end{array}$ & $146(46.2 \%)$ & \\
\hline
\end{tabular}

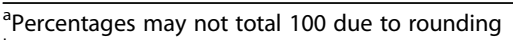

${ }^{b}$ Grammer school education includes the diploma corresponding to university entrance level, whereas secondary school education does not

education was 0.2 ( $p$-value 0.002), reflecting higher levels of $\mathrm{CHC}$ for higher levels of education. Subjects with grammar school education achieved a slightly higher mean score of person parameters compared to participants with secondary school education
$(432.88 \pm 77.72$ vs. $396.45 \pm 85.95$, mean difference $36.42 \pm 9.29 ; 95 \%$ CI 18.15 to $54.71 ; p<0.0001)$. No differences were found in the levels of $\mathrm{CHC}$ among the relevant sociodemographic variables under study (Table 2). 
Table 2 Differences in the levels of $\mathrm{CHC}$ for the relevant sociodemographic variables under study

\begin{tabular}{|c|c|c|c|c|}
\hline & Mean person parameters & Mean difference & $95 \% \mathrm{Cl}$ & $P$-value \\
\hline \multirow[t]{2}{*}{ Training status } & $\begin{array}{l}\text { Trainee }(n=174) \\
414.44 \pm 71.50\end{array}$ & $9.89 \pm 10.05$ & -9.38 to 29.18 & 0.33 \\
\hline & $\begin{array}{l}\text { Diabetes educators }(n=151) \\
404.54 \pm 104.01\end{array}$ & & & \\
\hline \multirow[t]{2}{*}{ Level of education } & $\begin{array}{l}\text { Grammar school }(n=142) \\
432.88 \pm 77.72\end{array}$ & $36.42 \pm 9.29$ & 18.15 to 54.71 & $<0.0001$ \\
\hline & $\begin{array}{l}\text { Secondary school }(n=176) \\
396.45 \pm 85.95\end{array}$ & & & \\
\hline \multirow[t]{2}{*}{ Further trainings in other fields of medicine } & $\begin{array}{l}\text { Yes }(n=146) \\
422.92 \pm 80.55\end{array}$ & $20.22 \pm 9.44$ & -38.79 to 1.65 & 0.07 \\
\hline & $\begin{array}{l}\text { No }(n=170) \\
402.69 \pm 86.23\end{array}$ & & & \\
\hline \multirow[t]{2}{*}{ Sex } & $\begin{array}{l}\text { Male }(n=17) \\
430.14 \pm 82.56\end{array}$ & $18.23 \pm 20.96$ & -23.00 to 59.46 & 0.39 \\
\hline & $\begin{array}{l}\text { Female }(n=303) \\
411.91 \pm 84.16\end{array}$ & & & \\
\hline \multirow[t]{2}{*}{ Native language } & $\begin{array}{l}\text { German }(n=197) \\
417.71 \pm 77.98\end{array}$ & $22.23 \pm 19.94$ & -17.07 to 61.53 & 0.27 \\
\hline & $\begin{array}{l}\text { Other }(n=17) \\
395.48 \pm 89.00\end{array}$ & & & \\
\hline
\end{tabular}

Table 3 presents correlations between the sociodemographic variables and levels of $\mathrm{CHC}$.

\section{Discussion}

This is the first study to survey the $\mathrm{CHC}$ of diabetes educators. The participants achieved a mean score of 409.84 $( \pm 88.10)$. Only the level of education seems to have had an influence on the level of CHC. Participants with a higher education degree had a slightly higher mean score of person parameters. However, the impact of slightly higher scores on the implementation of evidence-based practice principles in the participants' working environment remains unclear. A total of 325 healthcare professionals completed the $\mathrm{CHC}$ test; 174 participants had already completed their training to become a certified diabetes educator and 151 were still in training. No differences were found between the two groups regarding the level of $\mathrm{CHC}$. This is very likely, when reflecting the lack of implementation of evidencebased medicine methods within the $1800 \mathrm{~h}$ of training to become a certified diabetes educator, as skills in evidence-based medicine are needed to increase levels of $\mathrm{CHC}$.

Some previous studies have used the $\mathrm{CHC}$ test to measure the $\mathrm{CHC}$ of healthcare professionals [19-22]. In all the trials, the feasibility of training programmes in evidence-based medicine was tested. The samples comprised secondary school students (grade 11), university students, patients, patient counselors, consumer representatives, healthcare professionals and physicians. The achieved mean person parameters in these trials ranged from $466( \pm 121)$ in untrained participants to $671.90( \pm$ 51.38) in trained participants. Overall, diabetes educators in the present trial achieved competence scores slightly

Table 3 Multiple linear regression analysis adjusted for patient characteristics (dependent variable: person parameters)

\begin{tabular}{lll}
\hline & Regression coefficient & $\boldsymbol{P}$-value \\
\hline Training status & 0.014 & 0.851 \\
Country of birth & -0.160 & 0.060 \\
Level of education & 0.221 & 0.002 \\
Basic profession & 0.036 & 0.614 \\
Further trainings in other fields of medicine & 0.121 & 0.089 \\
Sex & 0.025 & 0.716 \\
Native language & 0.067 & 0.434 \\
Age & -0.059 & 0.426 \\
Professional experience & -0.162 & 0.136 \\
\hline
\end{tabular}


below those of untrained secondary school students or a self-selected group of patients and consumer representatives interested in evidence-based medicine [19-21]. These results underline the need for teaching strategies within the training curriculum for diabetes educators so that evidence-based medicine knowledge and skills can be increased.

Patients need unbiased information in order to make informed choices and to select the treatment that best fits individual patients' needs, values and preferences. Diabetes educators are therefore requested to deliver evidence-based information about the benefits and harm of the treatment options. $\mathrm{CHC}$ are indispensable for conducting consultations based on principles of shared decision-making, and poor health competences have been identified as a major barrier to the implementation of shared decision-making in diabetes care $[18,23,24$, 25]. Training in methods of evidence-based medicine to increase levels of $\mathrm{CHC}$ has become an integral part of the education curricula for healthcare professionals [26, 27] and the results of systematic reviews on the effectiveness of training in evidence-based medicine show some positive impact on the $\mathrm{CHC}$ of healthcare professionals $[28,29,30,31]$.

The level of $\mathrm{CHC}$ achieved by diabetes educators in this trial is insufficient to provide evidence-based information for patients with diabetes mellitus. It is indispensable that essential core competences of evidencebased medicine are included in the training curriculum for diabetes educators. A minimum set of required competences that teaching and learning programs should cover has been developed and described [32]. By integrating these competences, diabetes educators should be able to recognize the rationale for evidence-based practice, ask the relevant clinical questions, acquire, appraise and interpret the evidence, involve patients in the decision-making process and evaluate the strategy used.

This study has several strengths. Approximately 200 diabetes educators complete their training in Germany every year. Our sample comprised 151 diabetes educators in training and so almost three-quarters of all trained diabetes educators in one year. Most studies which measured $\mathrm{CHC}$ did not apply validated instruments. Knowledge and skills in evidence-based medicine were often determined by self-assessment [29, 33]. In our study, we used the validated $\mathrm{CHC}$ test to measure levels of $\mathrm{CHC}$.

The study also has limitations. The focus taken in our study on reading and understanding health information might have been too narrow to capture the wide range of cognitive and social skills that people need to make best use of health systems. The $\mathrm{CHC}$ test is strongly linked to the concept of evidence-based medicine. Therefore, other aspects of $\mathrm{CHC}$, such as the ability to make the best use of the health system or communicative skills are barely covered by the $\mathrm{CHC}$ test. We did not collect data on how many diabetes educators were offered the test, because recruitment was also performed via announcement and email lists. Therefore, we don't know if there are any differences in the characteristics between those who took the test and those who declined.

\section{Conclusion}

The $\mathrm{CHC}$ of the healthcare professionals who participated in this trial are limited and the present training of diabetes educators is unlikely to have an impact on these competences. In order to integrate research evidence and patients' values and preferences into the care of people with diabetes, core concepts of evidence-based medicine should be included into the curricula for diabetes educators.

\section{Abbreviations}

ADA: American Diabetes Association; ANOVA: Analysis of variance;

CHC: Critical Health Competence; $\mathrm{CHC}$ test: Critical Health Competence test; EASD: European Association for the Study of Diabetes; SDM: Shared decision making; SPSS: Statistical Package for the Social Sciences

\section{Acknowledgements}

We thank Daniela Büchner (DB) and Dörte Anders (DA) for entering all data into SPSS Version 21. We also thank Vivienne Krause for providing linguistic review.

\section{Authors' contributions}

$\mathrm{LH}$ wrote the first draft of the paper and performed the analysis. GM and AS reviewed and edited the manuscript. LH, GM and AS approved the final version of the manuscript.

\section{Funding}

This research did not receive any specific grant from funding agencies in the public, commercial or not-for-profit sectors. Open Access funding enabled and organized by Projekt DEAL.

\section{Availability of data and materials}

The datasets used and/or analyzed during the current study are available in an anonymised format from the corresponding author on reasonable request.

\section{Ethics approval and consent to participate}

All participants were told in written or oral form that their consent to participate is voluntary. The participants were informed about anonymized data collection and analysis. Informed consent was obtained from all participants by completing and submitting the $\mathrm{CHC}$ test. The study has been carried out in accordance with the Declaration of Helsinki and has been appoved by the ethical committee of the Medical Faculty of the Martin Luther University of Halle-Wittenberg (reference number 2017-75).

\section{Consent for publication}

Not applicable.

\section{Competing interests}

The authors declare that they have no competing interests.

\section{Author details}

${ }^{1}$ School of Nursing Science, Faculty of Health, University of Witten/Herdecke, Witten, Herdecke, Germany. ${ }^{2}$ Institute for Health and Nursing Science, Medical Faculty, Martin Luther University Halle-Wittenberg, Halle (Saale), Germany. 
Received: 12 October 2020 Accepted: 11 January 2021

Published online: 09 February 2021

\section{References}

1. Braun B, Marstedt G. Partizipative Entscheidungsfindung beim Arzt: Anspruch und Wirklichkeit [Shared decision-making: entitlement and reality]. In: Böcken J, Braun B, Meierjürgen R, editors. Gesundheitsmonitor 2014, Bürgerorientierung im Gesundheitswesen. Gütersloh: Bertelsmann Stiftung; 2014. p. 107-31.

2. Hamann J, Neuner B, Kasper J, et al. Participation preferences of patients with acute and chronic conditions. Health Expect. 2007;10:358-63.

3. Levinson $\mathbf{W}$, et al. Not all patients want to participate in decision making. A national study of public preferences. J Gen Intern Med. 2005;20:531-5.

4. Trevena LJ, Davey HM, Barratt A, et al. A systematic review on communicating with patients about evidence. J Eval Clin Pract. 2006;12:1323.

5. Cullati S, Courvoisier DS, Charvet-Bérard Al, Perneger TV. Desire for autonomy in health care decisions: a general population survey. Patient Educ Couns. 2011:83:134-8.

6. United Kingdom Medical Research Council. Consent: patients and doctors making decisions together. 2008. Available from: https://www.gmc-uk.org/ static/documents/content/Consent_-_English_0617.pdf. Accessed 2020 Jun 17.

7. Active Citizenship Network (ACN). European Charter of Patients' Rights. 2002 . Available from: http://ec.europa.eu/health/ph_overview/co_operation/ mobility/docs/health_services_co108_en.pdf. Accessed 2020 Jun 17.

8. Marteau TM, Dormandy E, Michie S. A measure of informed choice. Health Expect. 2001;4:99-08.

9. Gartlehner G, Matyas N. How contextual issues can distort shared decision making. Z.Evid.Fortbild.Gesundh.wesen (ZEFQ). 2016;118-119:17-23.

10. Légaré F, Ratté S, Gravel K, Graham ID. Barriers and facilitators to implementing shared decision-making in clinical practice: update of a systematic review of health professionals' perceptions. Patient Educ Couns. 2008;73(3):526-35.

11. Joseph-Williams N, Elwyn G, Edwards A. Knowledge is not power for patients: a systematic review and thematic synthesis of patient-reported barriers and facilitators to shared decision making. Patient Educ Couns. 2014;94:291-09.

12. Gaissmaier W, Gigerenzer G. Statistical illiteracy undermines informed shared decision making. Z Arztl Fortb Qualitatssich. 2008;102:411-3.

13. Lynagh M, Perkins J, Schofield M. An evidence-based approach to health promoting schools. J School Health. 2002;72:300-2

14. Sørensen K, Van den Broucke S, Fullam J, Doyle G, Pelikan J, Slonska Z, Brand $\mathrm{H}$. Health literacy and public health: a systematic review and integration of definitions and models. BMC Public Health. 2012;12:80.

15. Deborah C. Critical health literacy: a review and critical analysis. Soc Sci Med. 2011;73:60-7.

16. Inzucchi SE, Bergenstal RM, Buse JB, Diamant M, Ferrannini E, Nauck M, Peters AL, Tsapas A, Wender R, Matthews DR. Management of hyperglycaemia in type 2 diabetes: a patient-centered approach. Position statement of the American Diabetes Association (ADA) and the European Association for the Study of diabetes (EASD). Diabetologia. 2012;55:1577-96.

17. Deutsche Diabetesgesellschaft. Weiterbildungs- und Prüfungsordnung (WPO) zur Diabetesberaterin DDG. 2010. Available from: https://www. deutsche-diabetes-gesellschaft.de/weiterbildung/diabetesberaterin-ddg/ weiterbildungsordnung-und-plan.html. Accessed 2020 Jun 17.

18. Mühlhauser I, Kasper J, Meyer G. Fend : understanding of diabetes prevention studies: questionnaire survey of professionals in diabetes care. Diabetologia. 2006:49:1742-6.

19. Steckelberg A, Hülfenhaus C, Kasper J, Rost J, Mühlhauser I. How to measure critical health competences: development and validation of the critical health competence test (CHC test). Adv Health Sci Educ Theory Pract. 2009; $14: 11-22$.

20. Steckelberg A, Hülfenhaus C, Kasper J, Mühlhauser I. Ebm@ school-a curriculum of critical health literacy for secondary school students: results of a pilot study. Int J Public Health. 2009:54:158-65.

21. Berger B, Gerlach A, Groth S, Sladek U, Ebner K, Mühlhauser I, Steckelberg A. Competence training in evidence-based medicine for patients, patient counsellors, consumer representatives and health care professionals in Austria: a feasibility study. Zeitschrift für Evidenz, Fortbildung und Qualität im Gesundheitswesen. 2013;107:44-52.
22. Hinneburg J, Hecht L, Berger-Höger B, Buhse S, Lühnen J, Steckelberg A. Development and piloting of a blended learning training programme for physicians and medical students to enhance their competences in evidence-based decision-making. Z Evid Fortbild Qual Gesundhwes. 2020; 150:104-11.

23. Rodriguez-Gutierrez R, Gionfriddo MR, Ospina NS, et al. Shared decision making in endocrinology: present and future directions. Lancet Diabetes Endocrinol. 2016:4:706-16.

24. Scholte op Reimer WJ, Moons P, De Geest S, et al. Cardiovascular risk estimation by professionally active cardiovascular nurses: results from the Basel 2005 Nurses Cohort. Eur J Cardiovasc Nurs. 2006:5:258-63.

25. Sadeghi-Bazargani H, Tabrizi JS, Azami-Aghdash S. Barriers to evidencebased medicine: a systematic review. J Eval Clin Pract. 2014;20:793-02.

26. Montori VM, Guyatt GH. Progress in evidence-based medicine. JAMA. 2008; 300:1814-6.

27. Zwolsman S, te Pas E, Hooft L, Wieringa-de Waard M, van Dijk N. Barriers to GPs' use of evidence-based medicine: a systematic review. Br J Gen Pract. 2012;62:e511-21.

28. Horsley $T$, et al. Teaching critical appraisal skills in healthcare settings. Cochrane Database Syst Rev. 2011;11:CD001270.

29. Hecht L, Buhse S, Meyer G. Effectiveness of training in evidence-based medicine skills for healthcare professionals: a systematic review. BMC Med Educ. 2016;16:103.

30. Oude Rengerink K, Zwolsman SE, Ubbink DT, Mol BW, van Dijk N, Vermeulen $\mathrm{H}$. Tools to assess evidence-based practice behaviour among healthcare professionals. Evid Based Med. 2013;18:129-38.

31. Sihota, S., \& Lennard, L. Health literacy: Being able to make the most of health. 2004. Available from: http://citeseerx.ist.psu.edu/viewdoc/ download?doi=10.1.1.618.6960\&rep=rep1\&type=pdf. Accessed 2020 Jun 17.

32. Albarquoni L, Hoffmann T, Straus S, et al. Core Competencies in EvidenceBased Practice for Health Professionals Consensus Statement Based on a Systematic Review and Delphi Survey 2018. JAMA Netw Open. 2018;1(2): e180281. https://doi.org/10.1001/jamanetworkopen.2018.0281.

33. Albarqouni L, Hoffmann T, Glasziou P. Evidence-based practice educational intervention studies: a systematic review of what is taught and how it is measured. BMC Med Educ. 2018;18(1):177.

\section{Publisher's Note}

Springer Nature remains neutral with regard to jurisdictional claims in published maps and institutional affiliations.
Ready to submit your research? Choose BMC and benefit from:

- fast, convenient online submission

- thorough peer review by experienced researchers in your field

- rapid publication on acceptance

- support for research data, including large and complex data types

- gold Open Access which fosters wider collaboration and increased citations

- maximum visibility for your research: over $100 \mathrm{M}$ website views per year

At BMC, research is always in progress.

Learn more biomedcentral.com/submissions 